\title{
WOMEN WARRIORS: WHY THE ROBOTICS REVOLUTION CHANGES THE COMBAT EQUATION $^{1}$
}

\section{LINELL A. LETENDRE, COLONEL UNITED STATES AIR FORCE}

[This] should not be about women's rights, equal opportunity, career assignments for enhancement purposes for selection to higher rank. It is about, most assuredly is about...combat effectiveness, combat readiness, winning the next conflict....

- General Robert H. Barrow (retired) $27^{\text {th }}$ Commandant of the U.S. Marine Corps

So began the testimony of General Barrow before the Senate Armed Services Committee in June 1991 regarding his opinion on women in combat during which he gave his ultimate conclusion: "women can't do it....and there is no military need to put women into combat." That is about to change. The revolution in robotics and autonomous systems is poised to alter the debate from whether women are able to meet combat standards to how gender diversity in combat will improve the US military's fighting capability. Over the next decade, the US military will reap huge benefits from robotic and autonomous systems that will fundamentally change both the tools used on the battlefield and the approach taken to combat. Not only will robotic technology undermine the standard arguments against women in combat, but full gender integration across all combat roles will maximize American employment of autonomous systems and corresponding combat effectiveness.

To understand how robotics will change the equation of women in combat, this article first examines the current law and policy regarding women in combat positions, taking a close look at how the services are approaching the current DoD guidance to establish gender-neutral standards for all occupational specialties. While present policy and direction favors opening all 
combat career fields across genders, full integration is still more notional ideas than reality. To understand why, this article examines the arguments surrounding women in combat, both for and against. Next, the article highlights how robotics technology in development today will change the future battlefield by augmenting the physical capabilities of soldiers and lightening the loads carried by combat troops. Finally, this article assesses how robotic advancements not only defeat the naysayers of women in combat but should also compel senior leaders to integrate women into combat roles faster than currently planned. In sum, diverse combat teams will improve US future combat effectiveness in a robotic and autonomous systems fight.

\section{Women in Combat: Current Status of Law and Policy}

Though women have served in the Armed Forces in every conflict our nation has faced since its founding, the numbers of women and types of roles or occupational specialties have grown dramatically since World War II. This expansion of female participation in the military was driven in part by necessity following the implementation of the All-Volunteer Force in 1973 and in part by the equal rights movement. Despite these drivers, combat participation was specifically forbidden by statute until 1993. Following the recommendations put forth by the Presidential Commission on the Assignment of Women in the Armed Forces in 1992, Congress lifted the statutory restrictions surrounding women in combat and instead left decisions regarding appropriate occupational roles for genders to the Department of Defense. While these changes allowed women to serve in combat aviation roles, DoD excluded women from assignment to any unit below the brigade level whose primary role was to engage in direct ground combat. ${ }^{3}$

Following a number of Congressionally-mandated reports and the expanding role of women in combat roles in the War on Terror, DoD replaced the ground combat exclusion with a requirement for gender neutral standards in 2013. In a joint memorandum by Secretary of 
Defense Leon Panetta and the Chairman of the Joint Chiefs of Staff, General Martin Dempsey, DoD committed to removing "as many barriers as possible to joining, advancing and succeeding in the U.S. Armed Forces."4 DoD called upon the military services to integrate women into combat units as "expeditiously as possible" but no later than January 1, 2016. At that time, a service can also recommend that a particular occupational specialty or unit remain closed to women if the service is able to justify with "rigorous analysis of factual data" that women lack the abilities and skills necessary for the combat role. ${ }^{5}$ Such a waiver requires Secretary of Defense approval. Since this proclamation of full integration, services (particularly the Army and Marine Corps) have been working to integrate women into various combat preparatory courses such as the Army's Ranger course and the Marine Corps' Infantry Officers Course. Services are also struggling to define the standards for combat readiness in terms of physical fitness expectations and warfighting skills. The Marine Corps, for example, established a Ground Combat Element Integrated Task Force in October 2014 to develop a standards-based assessment for ground combat arms tasks. ${ }^{6}$

\section{Women in Combat: Arguments For and Against}

While General Dempsey justified the policy change as an attempt to "strengthen the joint force," critics of the integration of women in combat remain vocal. ${ }^{7}$ Since serious discussions of lifting the combat exclusion began in the early 1990s, the main arguments surrounding women in combat have focused on women's physical capabilities and the impact of gender integration on a unit's ability to fight effectively. Opponents point to clear differences between men and women's physical abilities: men typically have 30\% more muscle strength and $15-30 \%$ more aerobic capacity then women. ${ }^{8}$ These differences can have meaningful consequences when considering that an infantry soldier may carry packs of 100 pounds or more into combat. 
Women and men also carry loads differently, with women shortening their gait or stride when under heavy loads. While a 1996 Army study showed that a 24-week physical training course for civilian women enabled $78 \%$ of the group to carry and lift object over 100 pounds and improved the women's ability to run with a 75-pound pack, the fact remains that most men can out-lift, out-carry, and out-run the average woman. ${ }^{9}$

Outspoken critics, like Elaine Donnelly of the Center for Military Readiness, assert that such physical differences "detract from mission accomplishment" by impacting the cohesion and effectiveness of combat units. ${ }^{10}$ Social scientists who study group behavior have found that male groups thrive on competition, hierarchy, and conflict while female groups flourish on equality and cooperation. Men are more likely to be risk takers and be physically aggressive, while many women are culturally raised to be more nurturing and empathetic. ${ }^{11}$ Opponents of women in combat view such differences in group behavior negatively and infer that dissimilarities in group dynamics combined with physical capability deltas will result in a decline in unit cohesion and, subsequently, degraded combat effectiveness. ${ }^{12}$ They cite concerns that male soldiers will seek to "protect" women and that sexual tensions in a mixed combat unit will destroy morale and trust. ${ }^{13}$ The sum of such disruptions, proclaim antagonists, will destroy US combat capability. Proponents of gender integration into combat units reject such claims of a loss of combat effectiveness. Though recognizing physical difference between genders, proponents ask that DoD simply adopt a consistent combat standard and allow women who meet the standard to join the combat ranks. They note that women have fought in combat historically (e.g., the Soviet army in World War II and the "Long-haired Warriors" in Vietnam) and are successfully fighting in ground combat today. ${ }^{14}$ While not disputing differences of women's aerobic and anaerobic capabilities when compared to men, advocates reference that most soldiers in a 2008 Army 
Research Institute (ARI) study concluded that women do possess the physical strength, stamina, and mental capabilities to succeed in combat. ${ }^{15}$

Supporters also dismiss claims that unit cohesion would suffer if women were integrated into ground combat units. Social science literature demonstrates that unit cohesion is comprised of two parts: task cohesion and social cohesion. When opponents trumpet potential degradation of unit cohesion based on differences between the sexes, they normally refer to aspects of social cohesion or the emotional bonds of trust between group members. Studies have shown, however, that task cohesion — or the unifying force of a team focused on a combined mission—is the overwhelming contributor to overall unit cohesion...not social cohesion. ${ }^{16}$

Similar arguments about risk to unit cohesion have been raised and disproven numerous times in our military's history to include racial integration of ground forces, females joining combat aviation units, and most recently the service of openly gay and lesbian service members. Each integration experience has demonstrated that well-led teams derive their cohesion from a focus on the mission itself not on the differences or similarities of social make-up or backgrounds. Additionally, women-in-combat advocates dismiss concerns of sexual assault and decreased discipline in integrated units as problems appropriately handled through leadership and professionalism. ${ }^{17}$ Opening up more military jobs to women, proponents contend, will promote greater equity in promotions and positively affect the overarching military culture. ${ }^{18}$

While both proponents and opponents of women in combat have evidence and rhetoric to support their positions, the debate has principally centered on whether or not women can accomplish the job. Indeed, most advocates of gender-integrated combat units simply seek the opportunity of equality - allow women who can meet combat requirements to participate equally in the defense of their nation. To date there has been little discussion about how advances in 
technology—specifically robotics and autonomous systems and the corresponding changes in concepts of operation - will alter the debate. To begin to understand this effect, this article will now highlight a range of developing robotic and autonomous systems and their potential impact on the future of combat.

\section{Revolution in Robotics: A Changing Battlefield ${ }^{19}$}

The battlefield of the future will look exceedingly different from today's combat fight due in large part to advances in robotics and autonomous systems. From exoskeletons to robotic mules, technology is reducing the weight of combat gear and improving soldiers' physical abilities and load-carrying capabilities. The Defense Advanced Research Projects Agency (DARPA) kick-started innovation in this area in 2001 by funding labs, industry, and universities under the Exoskeletons for Human Performance Augmentation (EHPA) program. The goal of that 5-year program was to increase soldiers' strength and speed, provide greater protection from enemy fire, and improve soldiers' stamina while carrying loads. Some of the innovation DARPA funded under EHPA has transferred into demonstration projects in the services and fledgling programs of record. The Human Load Carrier (HULC), for example, is a hydraulicpowered exoskeleton made of titanium that allows soldiers to carry a sustained load of 200 pounds over a variety of terrain and to run at 10 miles per hour. While Lockheed Martin continues to upgrade HULC's battery power, the system currently allows eight hours of continuous field exercise or lasts several days for less exertive tasks like standing guard. ${ }^{20}$

Another DARPA initiative, called Warrior Web, began in 2011 and is funding projects to explore how to prevent musculoskeletal injuries from carrying heavy combat loads. Final designs are expected to allow a soldier to carry 100 pounds with $25 \%$ less effort and enable soldiers to run a 4 minute mile. ${ }^{21}$ Under this program, Harvard is developing a soft exoskeleton 
comprised of soft webbing woven into wearable fabric that assists joint movements in a soldier's legs. Weighing just 13 pounds, the Soft Exosuit does 15-20\% of the work associated with walking under heavy loads, thus enabling soldiers to walk farther. ${ }^{22}$ Another research institute has developed a system that serves as a robotic exomuscle near a soldier's calf. The system activates as a soldier walks and provides enough metabolic gain to make a 100-pound pack feel like it weighs 50 pounds. Future system developments will allow the robot to learn and selfadapt the rate of firing based on whether the soldier is walking or running. The final versions of these Warrior Web prototypes will be ready by $2016 .^{23}$

Other exoskeletons are designed to augment a soldier's physical capabilities. Ratheon Sarcos developed an exoskeleton, the XOS 2, that uses hydraulic energy and allows users to punch through three inches of wood and lift 200 pounds hundreds of times without tiring. ${ }^{24} \mathrm{~A}$ tethered version for military logistics is being fielded this year and an untethered version is due out in 2020. A DoD-funded research lab is developing an electrostatic forces gripper that will improve a soldier's ability to climb walls. Meanwhile, US Special Operations Command (SOCOM) began the Tactical Assault Light Operator Suit (TALOS) program in 2013 to bring the warfighter an array of special capabilities from full-body advanced armor and enhanced situational awareness to thermal management and command and control. The exoskeleton suit will include wearable computers and health monitoring systems capable of stabilizing wounds until care arrives. SOCOM aims to field TALOS by 2018 and is capturing innovations from 56 companies, 16 government agencies, 13 universities, and 10 national laboratories. ${ }^{25}$

Technological advances are also making equipment lighter for combat troops. The Massachusetts Institute for Technology (MIT), for example, is researching a liquid body armor that converts to a solid in milliseconds after a magnetic field or electrical current is applied. ${ }^{26}$ To 
cut down on the weight of battery packs carried by combat operators, the Office of Naval Research (ONR) is developing flexible solar panel to charge flat-form batteries with incredible efficiency. These batteries, called Marine Austere Patrolling System (MAPS), will weigh only six pounds and should be fielded in the next five years. ${ }^{27}$ Another DARPA-funded research center is developing an autonomously guided kite that generates tens of kilowatts of power simply through flight. Such a system would enable a combat squad to regenerate power autonomously and dramatically reduce the overall weight in batteries the unit must transport.

While such innovations will certainly help reduce the overall weight required to be carried by the individual soldier over the coming years, heavy loads will not be completely eliminated from a combat unit. Robotics, however, may change how the unit carries those loads. DARPA's Legged Squad Support System (LS3) program created a robotic mule capable of carrying loads of over 400 pounds over a wide variety of terrain. Affectionately known as "Big Dog," the robot is able to traverse terrain in one of three modes: leader-follower (where the robot follows close behind the human leader), semi-autonomously (where the soldier selects the destination but the robot selects the path), or a leader-follower corridor (where the robot follows the human leader but has wider latitude to select its preferred path). Though continued work is underway to develop a quiet electric motor to power the system (vice the currently loud diesel engine), the LS3 could be operational in the decade. ${ }^{28}$

Future combat units will also utilize unmanned ground vehicles (UGVs) for carrying loads and battlefield resupply and logistics. Such UGV reliance is operational today in the State of Israel, which is currently operating over $200 \mathrm{UGVs}$ in the field. Israeli UGVs range from the small, battery-powered, tele-operated UGVs, like RoboTeam's ProBot that can carry a payload of 550 pounds, to large UGV trucks and armored personnel carriers. ${ }^{29}$ Some Israeli robotics 
companies have been building UGVs for over eight years and have over 70,000 hours of operational field experience. G-Nius provides an applique to the customer's preferred platform to convert it to an unmanned system. The UGV can then be tele-operated, drive semiautonomously (where the system will stop when it sees an obstacle and rely on a human to resolve the obstacle before starting again), or operate fully autonomous, with the ability to recognize and resolve obstacles and make the best route planning decisions. ${ }^{30}$ The United States has explored UGV technology (to include some Israeli UGV technology) and laid out a roadmap for joint acquisition of UGVs in $2011 .^{31}$

Full integration and reliance on robotic and autonomous systems by US ground combat units is far from a "next generation or so" idea. Army Chief of Staff, General Raymond T. Odierno, recognizes that robotics will be an integral part of the force of 2025 and included robotics development as one of just eight lines of effort essential to achieving the Army's tenyear strategy. ${ }^{32}$ To that end, DARPA is investing in Squad X, a program that promotes manunmanned teaming within a dismounted infantry squadron. Squad X capitalizes on the interface between robotic technology and soldiers to improve precision engagement, command and control, detection of threats, and overall squad situational awareness. ${ }^{33}$ Whether improving an individual soldier's personal performance, carrying equipment to the battlefield, or enhancing a squad's combat lethality, robots are poised to change the nature of ground combat.

\section{Impact of Robotics Revolution on Women in Combat Debate}

The most apparent consequence of this changing battlefield and growing reliance on robotics systems is the impact on the physical requirements necessary for ground combat forces. The combination of robotic-enabled enhancements of a soldier's physical capabilities with lighter combat gear and robotic mules will quickly level the physical capability gap between men 
and women. For example, the exoskeletons being developed today result in a $25 \%$ improvement of physical strength and endurance - enough to close the aerobic and anaerobic delta between the average man and the average woman. With the ability to run faster, lift more weight, and carry weight for longer periods of time without physical injury, the average woman will meet or exceed combat capability standards... and that is before receiving targeted physical training and conditioning proven to improve women's physical prowess.

Skeptics might argue that robotic and autonomous systems will simply make male soldiers able to run faster and lift more thus eliminating any derived benefit for women. While in the initial implementation stages of robotic exoskeletons such argument may have merit, it would be myopic to think that technology will not one day eliminate all such distinctions. Indeed, the essential attributes of future warriors will almost certainly derive less from physical strength and more from technical abilities. ${ }^{34}$ Furthermore, such skeptical thinking neglects the affirmative arguments for capitalizing on gender diversity in the future robotic battlespace.

The US military needs gender diverse combat units to better implement robotic and autonomous systems technology on the future battlefield. Autonomy will not just change what tools soldiers use to fight but how the fight will be conducted. While advances like the Squad X system or TALOS may sound other worldly, technological progress is not the major driver of combat capabilities. As one roboticist explained, "Historically when one looks at major changes in combat, it hasn't been due to the gadget itself; it is the gadget that enabled the CONOPS to change.” ${ }^{35}$ To date, much of the US military's implementation of robotic and autonomous systems has simply been to replace an existing function performed by a human with a robot, especially when such a task is dull, dirty, or dangerous. Unfortunately, the potential of robotics will not be reached with such linear thinking. 
The US military must begin to field combat teams and grow combat leaders who are willing and able to think and implement autonomous systems in new and creative ways. To do this most effectively, combat teams need a diverse mix of individuals - including men and women. Diverse teams have been shown to think more creatively, accept change more readily, and solve problems more effectively. ${ }^{36}$ The same has proven true in the technology field. As one commentator explained, "Women bring unique talents and perspectives to the table in any field but they are particularly vital to a world of invention and innovation shaped by technology." ${ }^{37}$ A leading engineer in the defense industrial base remarked that she seeks out diverse teams especially in the area of robotics because such teams approach issues differently and find more effective and creative solutions to problems. ${ }^{38}$ It is this same creativity and problem-solving that the US military needs in its future robotic-propelled combat forces. Israel has already discovered the importance of utilizing women in the employment of robotic and autonomous systems. During the latest ground campaign, the Israeli Defense Forces (IDF) discovered that the best controllers of their UGVs were women. The IDF determined that their female soldiers possessed better focus and attention to detail—attributes necessary when viewing a multitude of sensors and employing robotic systems in ground combat. Additionally, IDF leadership found women displayed more self-restraint and deliberation before employment of weapons from the UGV, a skill-set much in demand during a conflict where collateral damage or killing of non-combatants was heavily scrutinized. The benefits of woman-unmanned teaming were so great the IDF placed all UGV operations in the hands of woman soldiers. While (in this author's opinion) all-female employment of robotic and autonomous combat technology tips the balance too far, the United States can learn from the Israeli experience and recognize the potential benefits of integrating women into all combat units. 


\section{A Question of When...Not If}

Given that robotic technology will eventually minimize the physical distinctions between genders on the battlefield and positive benefits exist for diverse employment of autonomous systems in combat, the question remains as to when to integrate ground units fully? Should the services proactively integrate women into ground combat roles in anticipation of a changing robotics battlefield, or should they wait for the technology to mature? In implementing SECDEF's 2013 guidance to set gender-neutral standards for ground combat units, the services have consistently stressed that physical standards and training will not change while simultaneously trying to study and justify why those standards exist in the first place. ${ }^{39}$ Simply put, the services are focused on determining what standards (physical and mental) need to be met for today's fight...not what qualities ground combat forces will need in the future. Such an approach will not position the force to maximize the potential of autonomous systems.

To best utilize robotic and autonomous systems, a diverse set of warriors need to be both on the battlefield implementing the technology and in positions of leadership to develop CONOPs and policy. Men and women need to be in the room when deciding ethical questions surrounding autonomous weapons employment, when developing requirements for future technological advances in robotic systems, and when formulating creative ways to employ the nascent technology. ${ }^{40}$ Women will not appear in the decision room overnight as the military grows its future leaders from the ground up. Every year the US military delays full and proactive integration of women into ground combat is another delay in the pipeline of developing female military leaders with the ground combat experience necessary to positively impact the application of robots in the battlespace. Thus, the question for today's senior leaders should not be whether women can pass today's current combat course but how soon the military can 
integrate women into ground combat squads in order to best employ robotic and autonomous

systems against the enemy.

1. Colonel Letendre received the 2015 National Defense University Women, Peace and Security Award for this article.

2. "SASC Testimony," YouTube, accessed March 19, 2015, https://www.youtube.com/watch?v=fy--whDNNKk.

3. David F. Burrelli, "Women in Combat: Issues for Congress," Congressional Research Service, Report R42075, May 9, 2013, 4-5.

4. Department of Defense, Elimination of the 1994 Direct Ground Combat Definition and Assignment Rule, January 24, 2013, by Secretary Leon Panetta and General Martin Dempsey, accessed March 3, 2015, http://www.defense.gov/news/WISRJointMemo.pdf.

5. Ibid.

6. "Ground Combat Element Integrated Task Force," U.S. Marine Corps, accessed March 17, 2015, http://www.gceitf.marines.mil/.

7. Cheryl Pellerin, "Dempsey: Allowing Women in Combat Strengthens Joint Force," Armed Forces Press Service, January 24, 2013, accessed January 16, 2015, http://www.defense.gov/news/newsarticle.aspx?id=119100. 2013, 6 .

8. Lisa Grossman, "The Right to Fight: Women at War," New Scientist, February 2,

9. Robert L. Maginnas, Deadly Consequences: How Cowards Are Pushing Women into Combat (Washington, D.C.: Regnery Publishing Inc., 2013), 79, 82.

10. Rosemarie Skaine, Women in Combat: A Reference Handbook (Santa Barbara: ABC-CLIO, 2011), 57.

11. Kingsley Browne, Co-Ed Combat: The New Evidence that Women Shouldn't Fight the Nation's Wars (New York: Sentinel, 2007), 28-29.

12. Ibid., 130-146; Maginnas, Deadly Consequences, 138-140.

13. Skaine, Reference Handbook, 62.

14. Ibid., 57, 59. Even critics recognize the contributions of women warriors throughout history. Maginnas, Deadly Consequences, 12-18.

15. Skaine, Reference Handbook, 61.

16. Department of Defense, Report of the Comprehensive Review of the Issues Associated with a Repeal of "Don't Ask, Don't Tell," November 30, 2010, 98-99.

17. Skaine, Reference Handbook, 38-39, 64.

18. Grossman, "Right to Fight." 
19. Unless otherwise noted, the research for this section was derived from numerous interviews with robotics industry engineers, academic research labs, and military personnel during the author's study (2014-2015) at the Dwight D. Eisenhower School for National Security and Resource Strategy.

20. Jeremiah Cushman, "Rise of Men Inside the Machines," Military Periscope Special Reports, December 18, 2014.

21. Ibid.

22. "Wearable Technology: Power Suit," Harvard, November 2014; "U.S. Military Funds Soft Exoskeleton for Enhanced Soldiers," The Engineer, September 18, 2014.

23. Jeremy Hsu, "The Weight of War: Modern Technology Tackles the Ancient Issue of Combat Loads," Popular Science, November, 2014, D61.

24. Cushman, "Rise of Men Inside the Machines."

25. John Keller, "Special Operations Needs Battle Suit with Cooling, Embedded Computers, and Sensors," Military \& Aerospace Electronics, October 2013; Cushman, "Rise of Men Inside the Machines.

26. Cushman, "Rise of Men Inside the Machines.

27. Hsu, "Weight of War."

28. Ibid.

29. "Probot," Roboteam, accessed March 19, 2015, http://www.roboteam.com/products/Systems/probot.

30. "Products," G-Nius Unmanned Ground Systems, accessed March 19, 2015, http://gnius.co.il/unmanned-ground-systems/index.php.

31. Department of Defense, "Unmanned Ground Systems Roadmap," Department of Defense, Robotics Systems Joint Program Office, July 2011, accessed March 17, 2015, http://www.peogcs.army.mil/documents/UGS_Roadmap_Jul11_r1.pdf.

32. Department of the Army, "FORCE 2025 and Beyond - SETTING THE COURSE," Secretary John M. McHugh and General Raymond T. Odierno, July 22, 2014, accessed March 15, 2015, http://www.arcic.army.mil/app_Documents/TRADOC_Memo_Force-2025-andBeyond-Setting-the-Course_06AUG2014.pdf; Department of the Army, "Training and Doctrine Command's (TRADOC) Technology and Capability Objectives for Force 2025 and Beyond," August 4, 2014, accessed March 15, 2015, http://www.arcic.army.mil/app_Documents/ARCIC_InformationPaper_TRADOC-Technologyand-Capability-Objectives-for-Force-2025-and-Beyond_18AUG14.pdf.

33. "Squad X Core Technologies Seeks to Bring Technological Advances to the Infantry Squad," DARPA, February 9, 2015, accessed March 16, 2015, http://www.darpa.mil/NewsEvents/Releases/2015/02/09a.aspx.

34. Caroline Kennedy-Pipe, "Women and the Military," Journal of Strategic Studies 23, no. 4 (2000), 32, 45 .

35. Defense contractor, interview with the author, January 30, 2015. 
36. Howard J. Ross, ReInventing Diversity: Transforming Organizational Community to Strengthen People, Purpose, and Performance (Lanham, MD: Rowman \& Littlefield, 2011), 2425.

37. Whitney Johnson, "Women are the Great Disruptors," in Innovating Women: The Changing Face of Technology, eds. Vivek Wadhwa and Farai Chideya, (Diversion Books, 2014), chap. 1, Kindle.

38. Katherine Lemos, interview with the author, March 8, 2015.

39. “A Few Good Women," David Martin, Sixty Minutes, aired March 15, 2015, on CBS, accessed March 19, 2015, http://www.cbsnews.com/news/female-marines-women-incombat-60-minutes/. The Marine Corps hired the Neuromuscular Research Lab at the University of Pittsburgh to conduct a "thorough scientific approach to testing and analysis of tactical requirements and musculoskeletal and physiological profiles of Marines." "USMC Initiative Launched," Neuromuscular Research Lab, accessed March 19, 2015, http://www.nmrl.pitt.edu/feature/usmc-initiative-launched.

40. For commentary on why a feminist approach to ethics in employing autonomous systems is essential from an international relations perspective, see Eric M. Blanchard, "The Technoscience Question in Feminist International Relations: Unmanning the U.S. War on Terror," in Feminism and International Relations, eds. J. Ann Tickner and Laura Sjoberg, (London: Routledge, 2011), 146, 162. 